\title{
Web 2.0 and academia
}

\author{
Michael Nentwich \\ Institute of Technology Assessment of the Austrian Academy of Sciences \\ 1030 Vienna, Strohgasse 45/5
}

\begin{abstract}
This contribution with an empirical focus analyses typical Web 2.0 services from the perspective of their use in academia. In particular social networking services such as ResearchGATE, Wikipedia as a tool for and by scientists, research blogging, microblogging like Twitter, and finally social tagging like Delicious and Zotero. The preliminary conclusion is that all of these new services are used in academia to varying degrees.
\end{abstract}

\section{Introduction}

In 2003, when this author finalised his study Cyberscience: Research in the Age of the Internet (Nentwich 2003), Web 2.0 (Knorr 2003; O’Reilly 2005) was still in its infancy. Today, it is everywhere: hundreds of thousands of people all over the world have become part of the rapidly growing social network that is fostering the development of the new services. Elements of some of the phenomena we would today subsume under the blanket term Web 2.0 were already visible in 2003: some academic journals were experimenting with open review procedures, known as "open peer commentary” or „open peer review” (Nentwich 2003, 371ff.; Pöschl 2004; 2005; 2007; 2009). There was also discussion of the possibility that the knowledge accumulated by the sciences could be stored in new kinds of hyper-databanks which would be collectively maintained and updated (Nentwich 2003, 270ff.). Even at that time, there was extensive discussion of the way in which readers could also become, to a certain extent, authors, or „wreaders“, which meant there would be an increase in multiple co-authorship and to a situation in which texts could no longer be attributed to particular authors (ibid., 293ff.). And one could already see at that time that the new media had the potential to, as it were, open new windows in the ivory tower of science and to contribute to the removal of the traditional, strict distinction between communication within science and communication between science and the outside world (ibid., 458f.).

In 2003, these considerations were still largely speculative. Now that Web 2.0 services have arrived, they have become much more immediate concerns. This presents us with a good opportunity to ask what (new) potential and what (specific) influence the new Web 2.0 services will have 
for and on science. The following overview of Web 2.0 services as used in academia has been carried out in an ongoing collaborative research project funded by the Volkswagen Foundation under the label of Interactive Science. ${ }^{1}$ It became clear that the setting up of collaborative knowledge resources (or net-based collaborative writing) is a development with great potential for use in science, and this is emphasised by the fact that scientists are already showing great interest in it. Virtual worlds could enrich distance communication in science, which has up until now largely been based on written texts, and it could even be the breakthrough that will make it possible to organise electronic conferences. Simultaneously, completely new forms of micro-publication are coming into existence, and so far there has been very little investigation of the effects these might have on formal and informal communication between scientists. Finally, the tools that make it easier to share information are also of interest for the scientific enterprise, which relies on cooperation and the availability of information and the building blocks of knowledge, both in its overall constitution and within smaller working groups.

\section{Social networks for scientists}

It was obvious from the start that attempts would be made to apply the new social networking model represented by Web 2.0 (such as Facebook, which is well known and mainly used for private purposes, and Xing or LinkedIn, which specialise in business contacts ${ }^{2}$ ) to the setting up of a scientific community. A number of attempts on these lines have now been undertaken: Nature Networks, which was launched by the eponymous publishing house and offers, among other things, blogs, employment opportunities, and fora devoted to particular topics; Academia.edu, which was originally chiefly concerned with setting up a global directory of universities and research institutes but now also offers services that are similar to those provided by Facebook (and which evidently cooperates directly with Facebook on the technical side); SciLink, Mendeley and Labmeeting, which concentrate on the exchange of academic articles; the much smaller networks Research Cooperative and ScholarZ.net; and ResearchGATE, which is probably the fastestgrowing of these services at present. ${ }^{4}$ All of these services are in essence address books which make it possible for „people who are registered to maintain their own contact data” (Bry \& Herwig $2009,30)$, and which also offer a number of supplementary services. A more detailed description of one of these services may serve as an illustration.

ResearchGATE was set up in May 2008, and less than two years later it already had a very respectable 300,000 members, of whom some $30 \%$ are thought to be active on a regular basis (according to an interview with one of the founders, cited in Hofmayer \& Wieselberg 2009). Members of the network provide a profile in which they describe themselves. As with other, comparable networks, private interests and similar details can also form part of the profile, but the main focus is on details of relevance to the individual's research - classification of one's work according to academic discipline, specification of one's main areas of research, and lists of one's own projects and 
publications. The members are also asked to upload bibliographies (for example EndNote documents) so that these can be shared with others. Literature references can also be given "marks" by the users, on a scale from one to five. Whenever a scholar logs on to ResearchGATE, and when $\mathrm{s} /$ he searches or browses the site, $\mathrm{s} / \mathrm{he}$ is made aware of relevant new literature, interesting potential contacts, and so on. This is done on the basis of the profile already provided, via what is known as "semantic matching”. It is possible to set up one's own personal network of contacts by sending invitations to other ResearchGATE members, and to people outside the network who are not yet participating. This network can then be visualised with the help of interactive graphics. Within the network, one can communicate via direct (web)mail or through group fora. These are thematically oriented amalgamations of scientists, and can be used for the purpose of exchanging sources via a shared archive of documents or circulating news about upcoming events via a calendar function, mutual assistance, voting, or the setting up of shared collections of documents. In addition, $R e$ searchGATE offers a meta-search function for anyone wanting to look for research material in certain databanks (e.g. PubMed and RePEc); the newest feature is an easy-to-use blogging platform (ResearchBLOG) and a related microblogging service (ScienceFEED). The final service offered at present is a list of job vacancies, and in the long term ResearchGATE hopes this service will be a source of revenue (Crotty 2008 thinks this will turn out to be the most promising of ResearchGATE's services). In the medium term, there is a plan to expand these services in different directions, by including for example an option enabling the groups to work jointly on texts.

According to a survey of ResearchGATEs founders (cited in Hofmayer \& Wieselberg 2009), a third of the platform's users employ the platform to find new research partners, another third use it to find information, approximately $15 \%$ use it to contact colleagues, and $12 \%$ use it for concrete research cooperation. It is not possible to determine in this paper whether, and if so to what extent, such networks can be used to good effect and efficiently in everyday scientific work, since it is obvious that the promised network effects can only be expected to appear after a trial period lasting more than a few days. No more detailed investigation has yet been conducted, but any such investigation would need to bear in mind that both this service and its competitors are constantly being developed further; in addition to quantitative analyses of the behaviour of users, an investigation would be best carried out by employing ethnographic participant observation methods.

\section{Wikis and online encyclopaedias}

For some time now, Wikis have been a familiar tool for scientific collaboration. A number of authors can work jointly on texts on a user-friendly web platform; fewer layout options are available than there would be if local word processing software were being used, but the joint production of texts can make use of the best available software support. ${ }^{5}$ Since 2005 a research project entitled OpenWetWare has been under way at MIT. ${ }^{6}$ This project is located in the field of synthetic biology, and one of its concerns has been to make explicit what has so far been „tacit knowledge“, for ex- 
ample circulating helpful advice in relation to the application of certain methods. This platform is also now being used for the coordination of research (Waldrop 2008; Bry \& Herwig 2009).

Wikipedia, the free Internet encyclopaedia, is based (like other projects launched by the Wikimedia Foundation, e.g. Wikiversity and Wikibooks) on the Wiki principle (Leuf \& Cunningham 2001). It has now matured as a worldwide undertaking, especially in terms of administration and quality control in relation to a huge number of co-authors. One could say that Wikipedia has since 2001 become the flagship for the idea of joint, global co-production of a knowledge base in which professional scientists also participate.

Wikipedia's content is extensive, though this content is subject to a quality control procedure that is very different from the operation of a traditional science system. A complex system of control and evaluation based on a range of functions, roles, criteria, and procedures functions in the background. Volunteers who have been serving in this capacity for some time, and also new users, are constantly on the lookout for mistakes and regularly contribute improvements. This means that the stock of content, which can in principle be deleted (but also replaced in its original form) at any time, is tied to certain criteria. Wikipedia offers a number of different ways in which users can work together, most significantly on the collaborative production of texts in the form of encyclopaedia articles. The discussion pages, on which users can exchange views and negotiate about content, are part of this cooperation platform. ${ }^{7}$ There is a number of what are known as Wikiprojects ${ }^{8}$ for special subjects, including scientific topics. These are initiatives related to particular subjects, dedicated to the expansion and improvement of articles belonging to a specific group of issues within Wikipedia. Wikipedia also contains discussion pages, which in a similar way offer a virtual space for collaborative work. Wikiprojects and task forces are where the substantive work in the shape of communication, the collation of sources, and summarising takes place. Although one of Wikipedia's basic principles is that it is not a place for original research, one cannot always draw this dividing line sharply; this platform does have the potential to canonise knowledge in certain areas.

One study of the scientific potential of Wikimedia projects (König \& Nentwich 2009) concludes that Wikipedia has a great deal of public relevance and is also increasingly relevant for the academic world, but is on the other hand dependent on scientific expertise in many areas of knowledge if it wishes to be accepted as satisfactory in qualitative terms. All in all, this leads to a sort of shotgun marriage between science and Wikipedia. On the scientific side, though, there is a degree of mistrust towards the unusual editorial and quality control processes, and so suspicion about the trustworthiness of the content; after all, the authors include both schoolchildren and professors. At the same time, the principle of practically anonymised authorship is not very attractive for professional scientists who might want to contribute. 


\section{Blogs: individual exhibitionism or the future of science?}

Online diaries, known as weblogs or blogs for short, have existed in the World Wide Web as a new form of publication since the mid-1990s. The initial rate of growth was slow, but since around 2000 their number has been growing rapidly. Bucher $(2009,148)$ calls them „conversational hypertexts”. Blogs can take different forms: semi-private diaries, blog journalism (grassroots journalism), thematically focused commentaries on current events, and blogs written by politicians or businesspeople which function as a new medium of external communication or marketing. Individuals, institutions, and also (small) groups can blog. As a rule, blogs use content management systems ${ }^{9}$ that are very easy to use and enable bloggers to provide links connecting their blog with other web resources, in particular other blogs (via "permalinks", i.e. individual addresses). Many blogs go further and give readers the opportunity to post comments, and this can lead to long discussions of individual blog entries. The term "blogosphere” is now used to refer to the interlinking of blogs, bloggers, and readers posting comments.

Many scientists also $\operatorname{blog}^{10}$ and they reflect on their role as bloggers both on their blogs and outside them. ${ }^{11}$ However, it appears that relatively few scientific analyses of scientists' blogs have been written so far (e.g. Schmirmund 2009; Stefanowitsch 2009). The following functions or forms of blogging by scientists can be identified (though in practice many blogs are a mixture of more than one of these forms):

(1) Blogs can be used to provide a public commentary on whatever is currently happening in science (in a particular discipline) or at the blogger's university. ${ }^{12}$ They thus function, like grassroots journalism blogs, as a kind of critical public sphere concerned with questions that are internal to science, and they are also sometimes used to expose undesirable states of affairs („whistle blowing").

(2) Commentaries on blog entries can fulfil the function of a discussion forum, and so serve as a kind of (semi-public) laboratory where scientific hypotheses are tested. Since blog entries always have a permalink together with a record of the date of posting, they can also serve to document the scientific process - even to the extent of demonstrating the copyright on certain ideas. ${ }^{13}$ This could be particularly useful for research groups scattered across a number of institutions. ${ }^{14}$

(3) Public blogs open new „windows in the ivory tower", and so contribute to external scientific communication when they inform a broader (Internet) public about new findings. They could also be used explicitly as a way of fostering the public understanding of science. This applies both to researchers and to scientific institutions. The linguist Stefanowitsch (2009) calls his blog a „popular-scientific” forum, and describes its contents as „everyday observations inspired by science.”

(4) Blog entries can also be interpreted as a new form of (pre)publication; most contributions made in this way are relatively short, which suits the scientific-discursive character of some specialist 
disciplines. In effect, the commentary function equips these publications with an open peer review procedure for quality control.

(5) In a period when online searches for material are becoming increasingly important, blogs can also serve as a tool for collecting information scattered across various Web 2.0 platforms. Within research groups this could take the form of joint blogs, ${ }^{15}$ thus providing a further possible collaboration platform.

(6) A blog can also be a kind of learning journal, something which, for example, accompanies an individual researcher through the writing of a dissertation. It can serve as an informal way of publishing or discussing preliminary findings, recording decisive moments in the development of the project, and documenting in diary form the progress of the dissertation. Some scientists have also experimented with keeping their lab diary as a publicly available document (this is discussed in Waldrop 2008, the experiment sometimes takes the form of a Wiki as well as a blog). ${ }^{16}$

(7) Blogs are also an attractive option for scientists wishing to establish their personal presence in the internal scientific sphere and in the external public sphere. In particular, they help younger scientists to establish a profile, get their work read, and ensure that this work reaches other scientists working on related questions. Because blogs are dynamic and make it possible to present substantive work in a constantly updated form, they are much more attractive than the early, static personal homepages (visiting cards in the Internet); they can be said to function as personal advertisements. Especially in times when there is growing competition for (adequately paid) scientific posts, this form of self-marketing could even become a necessity. At the same time, though, blogs present a challenge for anyone seeking to manage their own reputation online, since "the web never forgets - or hardly ever".

(8) Finally, there are also diaries in the strict sense kept by scientists who blog as private individuals without any direct reference to their scientific work. However, blogs (and the New Social Media in general) are making it increasingly difficult to maintain the distinction between professional and private life.

In sum, and as a preliminary finding, we can say that blogs certainly do have the potential to play a role in future scientific communication, both internally and externally. As the title of this section suggests, one undoubtedly needs to be something of an exhibitionist in order to present oneself to the world via a blog, though there are also many bloggers who use a pseudonym. But it may be that active participation in scientific discourse in the form of short Internet publications and commentaries (skywriting, as Harnad 1990 calls it) will soon be part of everyday scientific life, something one is socially expected to do and for which one will be rewarded. 


\section{Microblogging: a new scientific communication channel?}

The term microblogging is used to refer to those social network services which make it possible for Internet users to send short messages in real time, i.e. with no more than a brief delay, to any one who is interested. The content of these messages ranges from what are known as status messages ("Where am I?", "What am I doing?"), via links to other Internet sources ("Have you seen this?"), to commentaries on whatever is happening in the world, in one's own immediate surroundings, in the world of politics, and so on. The sequence of messages is represented chronologically in a blog, i.e. as a sort of online diary. There are a number of such services, ${ }^{17}$ some of which are also integrated into more comprehensive platforms such as Facebook and Academia.edu, but the special service Twitter $^{18}$ which went online in 2006, is probably the best known. Messages on Twitter, which are known as tweets, are limited to 140 characters. This sometimes leads to the use of an abbreviated form of language, ${ }^{19}$ and sometimes to the extreme condensation of the ideas being communicated (it is not the usual practice to cut a message up into a number of tweets). Depending on the settings chosen by the sender, messages can be sent to a selected group of other Twitter users or, and this is more frequently the case, to all those who have said they want to „follow” an individual user. One can either follow the „public timeline”, which means reading all tweets sent by all users anywhere in the world, or follow the standard practice of effectively subscribing to a selected group. It is also possible to search for certain keywords explicitly identified by Twitter authors. These are known as „hashtags”, and in this way one can read messages related to certain topics. One needs to set up a personal account in order to have access to Twitter as a reader or writer (though one can use a pseudonym); this is done via a web interface, but there are also applications for mobile devices (mobile phones, PDA) which provide access from any location where there is either mobile phone or, preferably, Internet reception. It is also possible to go further and, in addition to sending text messages, subscribe to a special service via which one can also integrate small images. ${ }^{20}$ Twitter now has many million users all over the world, and seems to be growing rapidly.

Many scientists are already using Twitter. ${ }^{21}$ The interesting question for our present purposes is: Is science in 140-character portions possible at all, what sort of science would that be, and what exactly can Twitter be used for in the scientific context? Will the "cyberscientist" (Thagard 1997) become a „scientwist“ (Bradley 2009)? The following different ways in which the service might be used can be identified, and there may be others:

(1) Collaboration: If we assume that (local or dispersed) groups of researchers agree to use Twitter as a medium of communication, it is well suited to the targeted exchange of information. However, because the messages that can be sent have to be very short, this exchange can only function within narrow limits. The service is used to announce conferences and other events, and to draw attention to publications available online and other Internet sources. It is not possible to conduct serious work on texts, nor can one discuss issues or formulate hypotheses that are anything more 
than ideas expressed as briefly as possible and which will therefore need to be properly worked out in another medium. The advantage of the medium is that it allows rapid and uncomplicated communication.

(2) Social components: Science is not just a matter of specialised work on substantive issues. It also consists of social relations which are established and maintained through informal and phatic communication. Conversations around the institute's coffee machine or in the corridor, or during a conference break, could take a kind of virtual form for dispersed research groups in the shape of a close-meshed network of Twitter messages which also go beyond work on the substantive issues as such.

(3) (Accompanying) Conferences: A good deal of tweeting now goes on around some conferences (and also in connection with other cultural and social events). The contents of these Twitter communications include organisational or substantive commentaries on the presentation being delivered at the moment of tweeting, making arrangements to meet up with colleagues, and gossip (Reinhardt et al. 2009). One could say that, parallel to the actual conference, an additional level of written communication and even reflection comes into existence which makes it possible for both participants in the real event (using their mobile devices, or via what is known as a "twitter wall”, a real time projection of relevant tweets in the conference room) and, to a certain extent, people who are not present, to follow and digest the arguments being presented. ${ }^{22}$ However, there have already been instances of conference organisers banning live blogging and tweeting to protect the confidentiality of closed conference sessions, for example to ensure that journalists only report when presenters have given their consent (Bonetta 2009).

(4) A channel for scientific marketing and communication: Twitter is being used by individuals based in scientific institutions, by research institutions themselves, ${ }^{23}$ and even by scientific journals ${ }^{24}$ to circulate to interested parties brief messages containing information about their own work, usually accompanied by an indication of where further information can be found online. Presumably this is a form of scientific marketing that makes it possible to reach a target group which would not be reached by the usual channels of press releases, newsletters, or mass e-mails. It also helps with internal scientific communication, for example as a way of announcing the publication of new articles $^{25}$ or informing people about upcoming conferences (Bonetta 2009 provides some examples of this).

(5) Teaching: The final point is that it would be worth examining the potential of microblogging in universities, especially in teaching. University administrators and lecturers are using Twitter to communicate more directly and efficiently with students by circulating organisational information via this service. Initial experiments with the use of Twitter in the classroom itself are also under way (e.g. Grosseck \& Holotescu 2008; Holotescu \& Grosseck 2009).

One of the major results of the study of Herwig et al. (2009) is, that as far as one can tell at this early stage, microblogging seems to be used for academic practices, whereby individual usage 
patterns and cultural (e.g. subject-related) factors play an important role. So far there are no classical incentive systems for using microblogging, but a number of indirect factors, e.g. that users may potentially acquire reputation or that the information exchange is extremely easy and swift. The main application fields for microblogging in science are consequently in the field of contextaugmented searching and publishing and with a view to reputation management; also in teaching and at conferences, microblogging may become established as a parallel communication channel; and the social components of open and informal communication may gain importance. In the end these authors conclude that microblogging is still a dynamic and fast developing new communication medium, which is not only offered by the market champion Twitter but is also increasingly embedded in other social media platforms. Consequently we reckon that microblogging will continue to function as a platform-independent communication principle, not least in academia.

\section{Tagging platforms: the future of information-sharing in science?}

Like e-mail and, in particular, electronic discussion lists (typical Cyberscience 1.0 applications), some of the Web 2.0 services discussed above, such as Twitter and blogs, are in principle already ideally suited to the sharing of information, i.e. making it available to others. There are some more specific services or platforms which go further than this and have as their goal the joint (cooperative) administering, sharing, and tagging of bookmarks or online literature. Delicious, ${ }^{26}$ for example,$^{27}$ is a service that has been available since 2003 and which enables registered users to store websites as favourites or bookmarks in a very simple way; these favourites are saved not on the user's hard drive, but (also) in the web. This means that one can access one's favourite sites from any location, and also that one can make them available to others. When bookmarking, users are asked to attach tags to these sites. In this way the web space is opened up from the bottom up, and it can then be used and expanded by all users (this is called a "folksonomy").

There is also the Zotero $^{28}$ service, which has been available since 2006 and can be used in a similar way. ${ }^{29}$ This is a literature administration software, which is integrated into the local web browser as an add-on and which enables users to save articles and online resources they have found in the web and to attach bibliographical meta-information to them. However, Zotero does not yet fully meet the requirements of modern literature administration systems (e.g. EndNote) which have additional functions supporting, for example, the integration of references into texts. Once one has registered and synchronised the locally stored literature entries with the Zotero server, one can access this databank oneself and can also, if one wishes, give others permission to access it. One can also set up groups, which can be either open or closed, and then share the synchronised references (and perhaps also the complete texts, which can be added as attachments) with the other group members.

Social tagging can also be used in combination with already established databanks, for example GoPubMed. ${ }^{30}$ This is an extension of the familiar medical literature databank which, in addition to 
the taxonomy established by automatic text-mining, also uses social tagging (see Crotty 2008; Bry \& Herwig 2009, 32). Finally, one can mention services like Slideshare ${ }^{31}$ (also available since 2006) as part of this category of new services designed to assist in the sharing and distribution of resources within the scientific community. Slideshare enables one to share presentation transparencies; in order to view the transparencies one only needs to be online, and a free account is all that is required if one wants to share them and add comments.

Up until now, these network-based services have not been used very frequently within the world of science. In the long term, though, they could replace centrally administered link lists, personal literature databanks, local bookmarks, and so on. Local research groups usually have access to a joint server, and so can exchange data, including literature databanks, directly. The Web 2.0 services described above are likely to be most valuable for dispersed research groups, since they place at their disposal an easy to use tool they can use to build up shared information resources.

\section{Outlook}

This empirical overview shows that academia has already adopted some of the Web 2.0 services. In our study (Nentwich 2009) we gave some preliminary answers to the question "How functional is web 2.0 for the sciences?" and discussed issues such as lack of time, surplus information, the incentive system, quality aspects, benefit expectations, the need to being constantly online, competition and transparency of research and authorship questions. We furthermore speculated on the possible consequences of web 2.0 for science, in particular with regard to the quality control system, internal and external scientific communication, the prospects of the integration of publication and conversation media and of worldwide digital integration via networks, possible democratisation effects and privacy issues. This analysis has to be continued, in particular as cyberscience is still a moving target for researchers. At any rate, this development too is a rewarding object of research for the fields of technology assessment and science studies. 


\section{References}

Bonetta, Laura (2009), 'Should You Be Tweeting?' Cell 139 (3): $452-453$ www.cell.com/fulltext/S00928674\%2809\%2901305-1.

Bradley, David (2009), 'scientwist'. 2009 (2009-01-08) www.sciencebase.com/scienceblog/scientwists.html.

Bry, François and Jana Herwig (2009), 'Kreidetafel und Lounge 2.0 - Der Einzug sozialer Medien in Technik und Wissenschaft', IMFachzeitschrift für Information Management und Consulting 24 (1): 26-33.

Bucher, Hans-Jürgen (2009), 'Das Internet als Netzwerk des Wissens. Zur Dynamik und Qualität von spontanen Wissensordnungen im Web 2.0', in: Heinz Fangerau and Halling Thorsten (Eds.), Netzwerke. Allgemeine Theorie oder Universalmetapher in den Wissenschaften? Bielefeld: 133-173.

Crotty, David (2008), 'Web 2.0 for BiologistsAre any of the current tools worth using?' 3.4. www.cshblogs.org/cshprotocols/2008/04/03/w eb-20-for-biologists-are-any-of-the-currenttools-worth-using.

Grosseck, Gabriela and Carmen Holotescu (2008), Can we use Twitter for educational purposes? 4th International Scientific Conference eLSE "eLearning and Software for Education" (April 17-18), Bucharest www.scribd.com/doc/2286799/Can-we-use-

Twitter-for-educational-activities.

Harnad, Steven (1990), 'Scholarly Skywriting and the Prepublication Continuum of Scientific Inquiry', Psychological Science 1: 342343

http://users.ecs.soton.ac.uk/harnad/Papers/H arnad/harnad90.skywriting.html.

Herwig, Jana, Axel Kittenberger, Michael Nentwich and Jan Schmirmund (2009), 'Twitter und die Wissenschaft. Steckbrief $4 \mathrm{im}$ Rahmen des Projekts "Interactive Science"'. ITA-Reports. Institut für TechnikfolgenAbschätzung. Wien, ITA (Dezember) epub.oeaw.ac.at/ita/ita-projektberichte/d22a52-4.pdf.

Hofmayer, Sören and Lukas Wieselberg (2009), 'Wissenschaft durch Internet effektiver gestalten - Social-Networking-Seite Re- searchgate. Interview mit Sören Hofmayer'. Science-On (17.08.) science.orf.at/science/news/156525.

Holotescu, Carmen and Gabriela Grosseck (2009), 'Using microblogging to deliver online courses. Case-study: Cirip.ro', Procedia Social and Behavioral Sciences 1: 495-501 www.sciencedirect.com/science?_ob=Mlmg \& imagekey=B9853-4VVXVR8-30-

1\&_cdi=59087\&_user $=464374 \&$ _orig $=$ search $\&$ cover-

Date $=12 \% 2 F 31 \% 2 F 2009 \&$ sk=999989998\&v iew $=c \& w c h p=d G L b V z z-$

zSkzV\&_valck=1\&md5=9a68ca52d53bb79bb b44426dd2203707\&ie=/sdarticle.pdf.

Knorr, Eric (2003), 'The Year of Web Services'. CIO: 90 (15.12.) www.cio.com.

König, René (2009), 'Eine Bewegung für die Wahrheit? Gesellschaftliche Wirklichkeitskonstruktion in Wikipedia am Beispiel alternativer Deutungen des 11. September 2001', Diplomarbeit, Universität Bielefeld.

König, René and Michael Nentwich (2009), 'Wissenschaft in Wikipedia und anderen Wikimedia-Projekten. Steckbrief 2 im Rahmen des Projekts Interactive Science'. ITAReports. Institut für TechnikfolgenAbschätzung (ITA). Wien, ITA (April) epub.oeaw.ac.at/ita/ita-projektberichte/d2-

2a52-2.pdf.

Leuf, Bo and Ward Cunningham (2001), The Wiki Way: Quick Collaboration on the Web. London: Addison-Wesley.

Nentwich, Michael (2003), Cyberscience: Research in the Age of the Internet. Vienna: Austrian Academy of Sciences Press hw.oeaw.ac.at/3188-7.

Nentwich, Michael (2005), 'Quality control in academic publishing: challenges in the age of cyberscience', Poiesis \& Praxis. International Journal of Ethics of Science and Technology Assessment 3 (3): 181-198 http://dx.doi.org/10.1007/s10202-004-0071-8.

Nentwich, Michael (2009), 'Cyberscience 2.0 oder 1.2? Das Web 2.0 und die Zukunft der Wissenschaft'. ITA manu:scripts. Institut für Technikfolgen-Abschätzung (November) e- 
pub.oeaw.ac.at/ita/ita-

manuscript/ita_09_02.pdf.

O'Reilly, Tim (2005), 'What is Web 2.0'. 2009

(30.09.) www.oreilly.de/artikel/web20.html.

Pöschl, Ulrich (2004), 'Open Access: Interactive peer review enhances journal quality'. Research Information www.researchinformation.info/risepoct04open access.html.

Pöschl, Ulrich (2007), 'Mehr Transparenz und Effizienz. Interaktives Open Access Publizieren und gemeinschaftliche Fachbegutachtung', Forschung \& Lehre (6): 334-335.

Pöschl, Ulrich (2009), Interactive Open Access Publishing \& Collaborative Peer Review for Improved Scientific Communication \& Quality Assurance. Kommunikationsformate und ihre Dynamik in der digitalen Wissenschaftskommunikation. Erste Meilensteintagung des Forschungsverbundes Interactive Science (9.-11.9.), Rauischholzhausen www.atmospheric-chemistry-and-

phy-

sics.net/pr_acp_interactive_open_access_pu blishing_icsti.pdf.

Reinhardt, Wolfgang, Martin Ebner, Günter Beham and Cristina Costa (2009), 'How People are Using Twitter during Conferences', in: V. Hornung-Prähauser, Luckmann, M. (Ed.), 5th EduMedia conference. Salzburg: Seiten elearningblog.tugraz.at/archives/2157.
Saunders, Neil, Pedro Beltrão, Lars Jensen, et al. (2009), 'Microblogging the ISMB: A New Approach to Conference Reporting', PLoS Computational Biology 5 www.ploscompbiol.org/article/info\%3Adoi\%2 F10.1371\%2Fjournal.pcbi.1000263.

Schmirmund, Jan (2009), Wissenschaftskommunikation über Social Media. Kommunikationsformate und ihre Dynamik in der digitalen Wissenschaftskommunikation. Erste Meilensteintagung des Forschungsverbundes Interactive Science (9.-11.9.), Rauischholzhausen

www.slideshare.net/JSCH/wissenschaftskom munikation-und-social-media.

Stefanowitsch, Anatol (2009), BlogKommunikation in der Wissenschaft am Beispiel des Bremer Sprachblogs. Kommunikationsformate und ihre Dynamik in der digitalen Wissenschaftskommunikation. Erste Meilensteintagung des Forschungsverbundes Interactive Science (9.-11.9.), Rauischolzhausen.

Thagard, Paul (1997), 'Internet Epistemology: Contributions of New Information Technologies to Scientific Research'. 2000 cogprints.org/674/.

Waldrop, M. Mitchell (2008), 'Science 2.0: Great New Tool, or Great Risk?' Scientific American www.scientificamerican.com/article.cfm? $\mathrm{id}=\mathrm{s}$ cience-2-point-0-great-new-tool-or-great-risk.

\footnotetext{
1 See www.oeaw.ac.at/ita/interactive or www.wissenschaftskommunikation.info.

$2 \quad$ Facebook (www.facebook.com); Xing (www.xing.com); LinkedIn (www.linkedin.com).

$3 \quad$ Nature Networks (network.nature.com); Academia.edu (www.academia.edu); SciLink (www.scilink.com); Mendeley (www.mendeley.com); Labmeeting (www.labmeeting.com); Research Cooperative (cooperative.ning.com); ScholarZ.net (scholarz.net).

$4 \quad$ www.researchgate.net.

5 There are a number of Wiki platforms, some of them freely available, for example mediawiki.org and tikiwiki.org.

$6 \quad$ openwetware.org.

$7 \quad$ A very interesting case study of negotiation processes in Wikipedia for a can be found in König König, 2009.

8 de.wikipedia.org/wiki/Wikipedia:WikiProjekt.

$9 \quad$ wordpress.org has effectively become the standard system.
}

10 Good initial overviews can be found at www.wissenschafts-cafe.net, www.scilogs.de and www.scienceblogs.de. 
See, for example, the manifesto of the „Hard Bloggin' Scientists”, at www.hardbloggingscientists.de.

One example of this is the philosophy blog ,quatsch” phaidon.philo.at/qu.

13 Though as Waldrop Waldrop, 2008 rightly points out, a blog or Wiki entry would be unlikely to carry much weight in a patent application - up until now, at least.

14 See e.g. www.wissenslogs.de/wblogs/blog/interactive-science.

15 For example: blog-de.scholarz.net/der-blog.

16 An example of this can be found here: www.scienceblogs.de/labortagebuch.

17 E.g. identi.ca; www.jaiku.com; www.yammer.com; www.plurk.com.

18 twitter.com.

19 There are a number of services one can use to shorten URLs, e.g. snurl.com.

20 twitpic.com.

21 See e.g. twitter.com/sciencebase/sci-comms.

22 One can find examples of collected tweets sent during a conference at: friendfeed.com/lindaunobel; delicious.com/J_SCH/solo09; Saunders et al. Saunders, Beltrão, Jensen, Jurczak, Krause, Kuhn and Wu, 2009 report on comparable Twitter-Friendfeed reporting from another conference.

23 One example among many is the Institute for Quantum Optics (IQOQI) of the Austrian Academy of Sciences (twitter.com/iqoqi).

24 See, e.g., these lists: scholarship20.blogspot.com/2009/07/twitter-journals-journals-that-tweet.html and mobilelibraries.blogspot.com/2009/05/scitechmed-journalspublications-on.html.

25 One interesting example in this regard is the Tweprints service (orbitingfrog.com/arxiv), which is used to announce and collect via Twitter papers published through the arXiv E-preprint archive of the physics community.

26 delicious.com.

27 There are a number of other social bookmarking tools, e.g. MyBookmarks (www.mybookmarks.com); Mister Wong (www.mister-wong.de); PennTags (tags.library.upenn.edu).

28

WWW.zotero.org.

29 There are a number of other social library tools, e.g. citeulike of Springer Publishers (www.citeulike.org); LibraryThing (www.librarything.de); Connotea, das Produkt of Nature Publishers (www.connotea.org); BibSonomy (www.bibsonomy.org); 2collab (www.2collab.com).

www.gopubmed.org.

www.slideshare.net. 